\title{
A QUALITATIVE INVESTIGATION EXPLORING
}

\author{
FEELINGS OF \\ INCOMPETENCE \\ AMONG COUNSELLING INTERNS
}

\section{Brad Daly and Nick Gazzola}

The aim of this study was to develop an understanding of how three master's level counselling students completing their internship manage their feelings of incompetence (FOI). In this study, FOI refers to occasions when a counselling intern believes that "his or her ability, judgment, and/or effectiveness as a therapist is absent, reduced, or challenged internally" (Theriault \& Gazzola, 2008, p. 20). The two theoretical approaches used in this study were the Imposter Phenomenon and the Self- Efficacy theory. Drawing upon Thematic Analysis, inspired by Grounded Theory, the results of this study demonstrate that FOI can have negative emotional and physical effects, but if managed appropriately can

also have benefits.

The work of mental health practitioners, such as counsellors and psychotherapists, requires a successful integration of professional capacities and expertise with personal attributes (Nissen-Lie, Rønnestad, Høglend, Havik, Solbakken, Stiles \& Monsen, 2015). As clinicians and researchers continue to recognize and emphasize the importance of the quality of the relationship between therapist and client (Cooper, 2004), a substantial degree of attention has shifted from investigating the specific techniques that may be responsible for change to exploring what qualities about an individual psychotherapist might facilitate change in clients (Aveline, 2005). This trend in the research emphasizes the importance of exploring self-care issues that effect psychotherapists, such as the psychotherapists feelings of incompetence (FOI) (Thériault \& Gazzola, 2005).

The aim of this study is to develop an understanding of how counselling students completing their internship manage their feelings of incompetence (FOI). In this study, FOI refers to occasions when a counselling intern believes that "his or her ability, judgment, and/or effectiveness as a therapist is absent, reduced, or challenged 
internally" (Theriault \& Gazzola, 2008, p.20). FOI is often used interchangeably with terms such as low self-efficacy, low mastery, and self-doubt. To conceptualize FOI, two theoretical approaches were used in this study which were the Imposter Phenomenon and the Self- Efficacy theory.

The Imposter Phenomenon is a term originally found in the work of Clance and Imes (1978) to refer to the state of an individual who appears to be successful from an external perspective but feels incompetent from an internal one. To investigate the key theoretical assumptions of the Imposter Phenomenon, Leary, Patton, Orlando, and Funk (2000) outlined its defining characteristics. They found that characteristics of the Imposter Phenomenon included a sense of being a fraud (an imposter), having a fear that others will find out that they are a fraud and regard them as a failure, and having difficulty internalizing achievements and strengths. Further, individuals experiencing the Imposter Phenomenon might not hold an accurate or realistic sense of their own competence, which undermines their ability to function at their highest level (Clance \& O'Toole, 1987). Interested in how the Imposter Phenomenon might affect practitioners of psychotherapy, Glickauf-Hughes and Mehlman (1995) conducted a study to investigate it. They found that Imposter Phenomenon among practitioners of psychotherapy was related to a tendency in practitioners to associate personal achievement with one's ability to meet the therapeutic needs of clients. They also determined that Imposter Phenomenon was a narcissistic problem that contributed to a therapist's burnout and FOI.

The construct of self- efficacy was also used in this study to conceptualize FOI (Bandura, 1986). When applied to the field of counselling, self-efficacy is defined as "one's beliefs or judgments about [one's] capability to effectively counsel a client in the near future" (Larson \& Daniels, 1998, p.180). It is generally understood that a therapist's self-efficacy can increase as he/she gains more experience (Easton, Martin, \& Wilson, 2008). Lent et al., (2009) studied how a trainee's self-efficacy changed following each of three sessions with practicum clients. They studied a sample of 98 Masters-level counselling trainees involved in their first practicum. The authors reported that at least two thirds of the participants experienced a small- to mediumsized change in confidence between each of their first three sessions.

Overall, when comparing studies that examine the Imposter Phenomenon to studies examining self-efficacy, there are noteworthy differences in how each theory conceptualizes FOI. The Imposter Phenomenon treats FOI as a relatively stable personality trait where one is either high or low on feelings of being a fraud. In contrast, self-efficacy understands FOI to be variable and a situationally-based construct having the potential to change with training, supervision, and counselling experience.

To determine the sources of FOI in therapists, Thériault and Gazzola (2006) interviewed eight experienced therapists and found that most of the participants 
reported the need to take responsibility for and stay aware of their FOI when they felt they had insufficient knowledge, a lack of training, or a lack of related experience working with specific client issues. Participants also revealed that their FOI was related to issues such as their ability to form relationships, their personal vulnerabilities, and their own states. The authors concluded that identifying known and effective coping mechanisms would improve therapists' ability to process their FOI.

FOI have been shown to have negative effects on a therapist's personal and professional quality of life, specifically contributing to his/her experiences of stress and burnout. Deutsch (1984) surveyed 264 psychotherapists to investigate the beliefs they held regarding their sources of stress and found that they attributed their stress to a sense of failure related to the therapeutic process and the outcomes of their therapeutic work. Farber and Heifetz (1982) investigated the relationship between therapists' "lack of therapeutic success" with their clients and their stress levels by conducting semi-structured interviews with 60 experienced therapists. Seventy-three. point three percent reported that a "lack of therapeutic success" with their clients accounted for "the single most stressful aspect of their therapeutic work".

Thériault, Gazzola, and Richardson (2009) examined FOI an experienced by a sample of ten novice therapists whose average counselling experience was two years and two months. The authors used semi-structured interviews to collect their data and used Grounded Theory for their analysis. The results indicated that FOI affected the participants' overall self-esteem and judgements about their sense of self-worth. The results also showed that FOI affected a therapist's personal life and caused a therapist to devalue himself/ herself.

Despite the negative consequences of $\mathrm{FOI}$, recent research has identified its benefits when therapists are aware of their self-doubts and manage them effectively. However, participants also reported that FOI motivated some learning experiences and increased their self-knowledge. In relation to self-care, the participants reported engaging in self-soothing internal dialogue, prayer, and meditation to manage FOI. Participants also shared their FOI with others in their lives to normalize the experience. Overall, counsellors expressed an increased ability to manage their FOI as they obtained more professional and personal experience. Nissen-Lie et al. (2015) examined therapists' ability to cope with their professional self-doubts (PSD) and the effects of their coping strategies on their client's interpersonal distress. The results revealed that when therapists cope with their PSD using positive strategies such as dealing actively with the problem, seeking consultation, and problem solving with the client, that the client's interpersonal distress was reduced. In contrast, if they coped with their struggles using negative strategies such as avoiding the problem or acting out frustrations in therapeutic relationship, there was less change in distress in their clients. 


\section{Unique Challenges for Counsellors in Training and Novice}

\section{Therapists}

Past research indicates that there is a discrepancy between how counsellors are trained and the knowledge and skills they receive regarding self-care and selfawareness. Pompeo and Levitt (2014) demonstrate that graduate counsellor training programs and internship supervisors frequently outline the importance of self-care and self-awareness with students and interns, yet the authors found a disconnect between course material and practical application. In other words, this study found that counsellors in training were being taught about self-care and self-awareness but were not provided with sufficient opportunities to practice coping strategies.

Regardless of whether training programs and supervisors were providing their students and interns with sufficient knowledge and opportunities to practice and improve their self-care strategies and gain self-awareness, novice therapists appear to face unique challenges compared to experienced therapists. For example, Orlinsky et al. (1999) found that insecurity, performance anxiety and poor self-perceived mastery of therapy was highest (83.2\%) among therapists with slightly over a year of experience or less compared to $52.3 \%$ among therapists with five years or more experience. Further, this study found that novice therapists were at a unique risk for experiencing FOI (Orlinsky et al. 1999).

\section{The Significance of Researching How Do Counselling Students Manage FOI}

FOI are widespread among therapists regardless of their levels of experience (Thériault \& Gazzola, 2005, 2006, 2008), but are particularly acute in novice therapists (Orlinsky et al., 1999). Novice therapists were found to lack the experience necessary to both implement effective self-care methods and develop a high level of selfawareness (Knudsen et al., 2013; Mor Barak et al., 2001). Therefore, it is concerning that FOI remains a taboo topic among students, professors, and even supervisors in counselling (Thériault et al., 2009). Our study is important because there is a clear gap in the research exploring how counselling interns manage their FOI.

\section{Research Design}

Our study drew from Thematic Analysis, inspired by Grounded Theory, to answer the central research question: how do counselling students within their internship manage their FOI? Our epistemological and ontological stance is based in social constructivist and relativist worldviews. Therefore, we believe that multiple realities exist that must be understood and interpreted within a wider cultural context. Further, we believe that reality is subjective and gained from the perspectives of a variety of participants. My (Daly) positionality is shaped by a) four years of volunteer 
internship and work experiences providing counselling services, b) an undergraduate thesis exploring the self-care strategies mental health professionals use to manage vicarious trauma, and c) graduate studies in Counselling Psychology. This study applied an inductive approach as its methodological stance by starting with an analysis of the data, drawing specific observations and working towards developing codes, themes and subthemes.

\section{Methods}

As the primary researcher, I (Daly) recruited participants by approaching Counselling Psychology students who were currently completing their internship and asked them if they would be interested in participating in a study exploring how counselling students manage their FOI. A convenience sample took place and three participants, two Caucasian women and one Caucasian man between the ages of 2333, were recruited and interviewed. All the participants began their internship in September 2016 (Table \#1- Participant Characteristics). All participants were enrolled as Counselling students at the University of Ottawa and were in the process of completing their internships.

Table \#1- Participant Characteristics

\begin{tabular}{|c|c|c|}
\hline PARTICIPANT 1: JORDAN & PARTICIPANT 2: TESS & PARTICIPANT 3: KYLIE \\
\hline $\begin{array}{l}\text { - Counsellor at a } \\
\text { University }\end{array}$ & $\begin{array}{l}\text { - Counsellor at a } \\
\text { Community Agency }\end{array}$ & $\begin{array}{l}\text { - Counsellor at a } \\
\text { Community Agency }\end{array}$ \\
\hline $\begin{array}{l}\text { - Provides short-term care } \\
\text { for clients aged } 18-25 \\
\text { with a narrow range of } \\
\text { issues. }\end{array}$ & $\begin{array}{l}\text { - Provides short and long- } \\
\text { term care for clients aged } \\
20-65 \text { with a diverse } \\
\text { range of issues }\end{array}$ & $\begin{array}{l}\text { - Provides long-term } \\
\text { care for clients aged } \\
\text { 18-25 with a diverse } \\
\text { range of issues. }\end{array}$ \\
\hline
\end{tabular}

\section{Data Collection}

Upon gaining ethics approval and verbal consent, participants were given a written consent form which I reviewed with them. Upon obtaining signed consent forms, I (Daly) interviewed each participant using one-on-one, 60-90-minute semistructured interviews with open-ended prompts. Each interview was audio recorded and transcribed verbatim (Corbin \& Strauss, 2014).

Data Analysis

This study drew upon Thematic Analysis, inspired by the rigorous coding methods used in Grounded Theory (Braun and Clarke, 2006), but did not aim to reach data saturation or develop a theory due to the constraints and aim of this exploratory master's pilot project. Thematic Analysis was used to identify, organize, and understand common participant experiences. Open and axial coding were used to analyze the data following Braun and Clarke's (2006) six phase approach to Thematic 
Analysis: 1) Familiarisation with the data 2) Generating initial codes 3) Searching for themes 4) Reviewing themes 5) Defining and naming themes 6) Writing up. Additionally, a constant comparative method was used during data analysis.

\section{Results}

Our study identified three primary themes and in each primary theme, subthemes were identified. The first primary theme was labeled as 'Sources and Consequences of FOI' and included 'Emotional' and 'Physical' consequences as subthemes. The second primary theme was labeled 'Actions of the Intern Related to the Management of FOI' and included 'Accessing Support Networks', 'In-Session Management Strategies', and 'Self-Care' as subthemes. The last primary theme identified was labeled as 'Correctives' and included 'Positive Aspects of FOI' and 'Lessons Learned' as subthemes.

\section{Theme 1: Sources and Consequences of FOI}

The theme entitled 'sources and consequences of FOl' demonstrates how participants were affected by FOI during their internship. The participants indicated that FOI affected them both emotionally and physically. I started each interview by having clients recollect experiences that they enjoyed in their internship. Then, I investigated if the counselling interns experienced FOI. Each of the participants expressed doubts in their counselling abilities, and in situations in which they genuinely did not know what to do. For Kylie, the experience of FOI was evident when she stated:

It's tough and I find that it makes me wonder if I'm the right person to be talking to them. - Kylie

In addition, the participants reported they were affected in numerous ways and suggested that they experienced FOI at different times and intensities depending on the situation at hand. Jordan said:

When I have those days, you know I mean it comes in waves. Some days are better than others - Jordan

Finally, the diversity of client issues and the inability to know what to expect was reported as a source of the participants FOI:

You are going in and you have no idea what someone might be coming in with and as a student you feel so pressured and compelled to know absolutely everything before you go in. Like an encyclopedia, but it's impossible - Tess 


\section{Subtheme 1A: Emotional Consequences}

The FOI that the participants experienced seemed to influence their emotional lives. Emotional consequences of FOI that were evident for each of the participants were stress, guilt, fear, and isolation. They indicated that they were all experiencing stress but reported different causes of this stress. For Jordan, the stress was a result of reading the client's file before their first session and feeling intimidated about how to approach the client's issues.

and I read their reasons for why they want to come for counselling and when I read that, that's the time that it is intimidating because it's just everything thrown at you and I'm like I don't know what I'm to do with that, I have no idea - Jordan

In contrast, for Tess and Kylie, the stress they experienced seemed to be rooted in their rumination over what occurred within their sessions and on thinking back about where they could have improved.

I definitely just think back, I try to play back the conversation in my mind over and over and over again and pick apart not only the words that I'm using but I'm also picking apart my tone - Kylie

All the participants stated they felt a sense of guilt and fear about making mistakes with clients which is consistent with Clance and O'Toole's (1987) description of the Imposter Phenomenon. For example, Tess had a session where she was cocounselling with her supervisor and the client was experiencing an episode of psychosis that she was unaware of.

I just feel a sense of, guilt. I feel like I did something wrong and that could have potentially harmed my client. It sucks. - Tess

Glickauf-Hughes and Mehlman (1995) described how this sense of guilt about and fear of making mistakes with clients can lead to therapists losing a sense of reward and joy in their therapeutic work. Finally, the participants reported feeling isolated within their FOI. When they began to feel incompetent, they found it very difficult to think of anything but their FOI. Therefore, the isolation the participants experienced made it more difficult for then to employ effective strategies to manage their FOI and instead they felt alone in their respective struggles.

But it's more like I want to close myself in. So it affects me like that night, where I feel like the world is closing around me - Tess

\section{Subtheme 1B: Physical Consequences}

All of participants reported experiencing physical consequences due to their FOI. The main physical consequencs was feeling of being drained and bogged down. Jordan 
reflected that there is a constant element of feeling incompetent but when it builds up, it reaches a threshold that becomes "insurmountable". At this point, he reported that the FOI physically affected him. For example, he mentioned:

So exactly, the FOI when I feel like it bogs me down, when I feel like it is unsurmountable, then it affects me - Jordan

Also, Tess described how the counselling profession requires a therapist to be engaged, alert, and compassionate at all time. She described how having to use these qualities all the time is exhausting and that when she wasn't able to maintain these qualities she felt incompetent.

I notice that I get a little shorter and I get a little less compassionate once I get home because it's so exhausting. - Tess

Theme 2: Actions of the Intern Related to the Management of FOI

Each of the participants engaged in a variety of strategies to manage their FOI. They reported that they managed their FOI for themselves but also for their clients with comments such as: I'm doing this for myself, but also in the end, I'm also doing it for them.

The participants also expressed that they managed their FOI using a combination of methods instead of relying solely on one method. Tess was able to conceptualize the importance of managing FOl in a holistic manner stating that:

Self-care is a lot more than drinking water, doing yoga and having a bubble bath. It's a lot more about having a good work life balance, having good social support and having a really good organization that backs you. - Tess

To conceptualize the different strategies that the participants used to manage their FOI, each strategy was grouped into three subcategories: support, in-session, and self-care.

\section{Subtheme 2A: Accessing Support Networks}

Each of the participants expressed the importance of using support systems to manage their FOI. Specifically, each participant reflected that family, friends, supervisors, colleagues, and their internship class were all support systems that helped them to manage their FOI. Notably, the different support systems all had the common themes of being open, trustworthy, and non-judgmental. An example of this was when Jordan expressed:

Reaching out to people. Or even like a friend. With FOI- I got to my supervisors who I have a really good rapport with. I trust them and I'm very open. - Jordan 
Also, for Tess, the different support systems were used for different purposes.

Whenever I debrief with my supervisors and colleagues there that emotional support for me. But there is also that kind of spreading of that responsibility. I'm resourcing for myself and for my client.... And then with colleagues it's more so just validation - Tess

Finally, for Kylie, the internship class provided her with an opportunity to disclose information that she would be unable to do with her family members:

I kind of wish that I had more support there or just more time to talk because I can't go home and tell my mom...oh this happened....but I can get support in my internship course. - Kylie

\section{Subtheme 2B: In-Session Management Strategies}

Each participant reported that there were certain in-session methods that they relied on to manage their FOI. The participants said that these were the techniques that they learned in their skill development counselling course, which is a course dedicated to applying practical counselling skills.

The good thing about this program is that we really talk about the therapeutic alliance and how to build on that. - Tess

Then I was reminded to just take a step back and use those tools that I was taught in the skill development counselling course - Jordan

Specifically, when experiencing FOI within a session, each of the participants found that being open, transparent, present, non-judgmental, authentic, and patient with their clients really helped to manage their FOI.

Being in the present with a client helps with FOI. If I don't know what to say with a client, why don't I just be with them? - Jordan

I feel like they really appreciate (being transparent) when it's more collaborative than solely speaking as the expert. - Tess

Each of the participants said that using specific techniques before employing these 'skills' made them feel like they were taking the role of expert instead of walking with the client in their shoes and allowing the client to trust them.

\section{Subtheme 2C: Self- Care}

Each of the participants in this study emphasized the importance of self-care in the field. They felt that their clients are usually very vulnerable and require a 
counsellor who maintains a healthy mindset through practicing self-care methods. Tess and Kylie expressed the importance of self-care by stating:

"Self-care is really important because it's such an emotionally demanding field" - Tess

The specific self-care methods that the participants found helpful included engaging in meditation, psychoeducation, leaving work at work, and self-compassion. Meditation had the effect of increasing the participant's awareness of the present moment.

I meditate just to feel centered and this is something I try to translate to a client as well - Jordan

Yeah, I meditate and I'm in a mindfulness group which are helping. -Kylie

Additionally, psychoeducation was a way in which participants could ease the pressure of their FOI. Specifically, if they felt that their counselling skills were lacking in certain areas, they would engage in homework activities to prepare themselves for similar situations in the future.

I will go home and my homework of the day will be researching absolutely everything that I can. It helps me feel better and more prepared going into the next session - Tess

Leaving work at work was an aspect of self-care that each of the participants recognized was important. Specifically, the participants found that when they brought their work home with them they were never able to get a break from it, which they felt could lead to negative consequences such as burnout. To manage her FOI, Tess explained that she has two different 'hats' that she used to make sure that work stayed at work. She described the negative consequences of leaving her counsellor hat on when she gets home from work:

I call it my different hats. When I'm in session with a client, I wear my counsellor hat and I don't ruminate and I don't feel incompetent. That's like a good thing I guess. But after the session it all starts to explode. The hat comes off and I'm like what, that feeling is terrible - Tess

\section{Theme 3: Correctives}

Each of the participants described correctives that they used to further their growth as a counsellor. They began by identifying the benefits of their FOI, then they revealed the lessons that they learned through their experience as an intern experiencing FOI, and finally they identified areas of their training that could be improved to better manage their FOI. 


\section{Subtheme 3A: Positive Aspects of FOI}

The participants observed that although FOI had negative consequences, it also had some benefits. The benefits were described as ways that not only allowed them to manage their FOI but also to provide more effective care for their clients. Jordan reflected that by staying on his toes, he was able to recognize the importance of managing his FOl in-session.

FOI kind of helps me to create that beginner's mind, it keep me on my toes, and it helps me to establish good rapport with a client. - Jordan

Also, the FOI that the participants experienced motivated them to learn more about the counselling profession. Further, it revealed to them that mistakes can in fact occur within the counselling setting and a counsellor's skills can improve by having knowledge.

The FOI I've experienced during my internship has been very humbling and made me realize that there's so much that I still have to learn.... I feel like I am going in with like Tabula Rasa, I'm like I know absolutely nothing. Learn everything - Tess

\section{Subtheme 3B: Lessons Learned from FOI}

The participants in this study reported that the FOI they experienced taught them several lessons about how to become more effective counsellors. Specifically, the participants reported that giving time to process their sessions and recognizing the complexities of the profession were important lessons that they learned throughout their counselling experiences. Jordan expressed that when he took on too many internship hours, he felt that he was doing a disservice to his clients.

If I give myself like less of a work load I could take more time to process and conceptualize with what the client needs.... Right now I actually give myself less hours so I can process and be open to suggestions. - Jordan

Recognizing the complexities of the profession allowed the participants to have compassion for themselves, thus helping to manage their FOI. They reflected that if they were unable to recognize these complexities, they would be constantly beating themselves up. The awareness of being in a complex profession allowed them to come to a deeper appreciation of the role counsellors have.

"Like I look up things that I don't get...so it's so much more complex and bigger than me that it makes me realize and be appreciative of all the different fields as related to counselling" - Tess 


\section{Discussion}

Taken together, this study shows that FOI can have negative emotional and physical effects but can also have benefits if managed appropriately. Specifically, the participants in this study managed their FOl by using support networks that were open, trustworthy, and non-judgmental, by applying strategies in-session, such as being open, transparent, present, non-judgmental; authentic and patient, strategies which they learned from their skill development counselling course; and finally, by engaging in self-care methods such as meditation, taking part in psychoeducation, and leaving their work at work. This study found that the strategies used by participants to manage their FOI allowed them to feel more capable and competent in their ability to provide effective mental health services, thus decreasing their feelings of being an imposter and increasing their counselling self-efficacy. The FOI that the participants experienced had several benefits such as keeping them on their toes and motivating them to learn more. In addition, they learned to not take feedback personally, to be aware of the complexities of their profession, and to take time to process their sessions.

Implications

Each of the participants expressed a need to discuss FOI in training and to have more opportunities to disclose the FOI they were experiencing. The concerns expressed by the participants in this study identify a need for future research into FOI among counselling interns because on one hand, counsellor educators and supervisors have the role of supporting interns but on the other hand they have the responsibility to evaluate them (Worthen \& McNeill, 1996). This leaves the counselling intern in the predicament of either coming off incompetent to their evaluators or suffering with their FOI in silence. Overall, to experience the full benefits that FOI have to offer and minimize its negative consequences, there must be a dialogue between counselling interns and their educators/supervisors that addresses experiences of FOI in an open, trustworthy and non-judgmental manner.

\section{Limitations}

A limitation of this study was the small sample size. Creswell (2013) suggested that a study using Grounded Theory often conducts interviews with 20-60 individuals. The small sample size in this study did not allow for the data to be saturated and therefore the themes presented are not to be interpreted as generalizable to all counselling students completing their internship experience and managing their FOI. Another limitation was that I did not implement all of Creswell's (2013) recommended validation strategies due to the limited timeline for this study. Specifically, I was not able to apply prolonged engagement and persistent observation in the field. Finally, this study was not peer reviewed and did not achieve triangulation where 
"researchers make use of multiple and different sources, methods, investigators, and theories to provide corroborating evidence" (Creswell, 2013, p.208).

\section{References}

Bandura, A. (1986). The explanatory and predictive scope of self-efficacy theory. Journal of Social and Clinical Psychology, 4, 359-373.

Braun, V., \& Clarke, V. (2006). Using thematic analysis in psychology. Qualitative Research in Psychology,3,77-101. doi:10.1191/1478088706qp063oa

Canadian Psychological Association. (2000). Canadian Code of Ethics for Psychologists. Retrieved from: http://www.cpa.ca/cpasite/UserFiles/Documents/Canadian\%20Code\%20of\%20Ethi cs\%20for\%20Psycho.pdf

Ciance, P. R., Imes, S. A. (1978) The imposter phenomenon in high achieving women: Dynamics and therapeutic intervention. Psychotherapy: Theory, Research \& Practice, 15, 241-247. doi: 10.1037/h0086006

Clance, P., \& O’Toole, M. (1987). The Imposter Phenomenon. Women \& Therapy, 6(3), 51-64. doi: 10.1300/J015V06N03_05

Cooper, M. (2004). Towards a Relationally-Orientated Approach to Therapy: Empirical Support and Analysis. British Journal of Guidance and Counselling, 32(4), 451-460.

Creswell, J. (2013). Qualitative inquiry \& research design: Choosing among five approaches ( $3^{\text {rd }}$ ed.). Thousand Oaks, CA: Sage Publications.

Easton, C, Martin Jr., W. E., \& Wilson, S. (2008). Emotional intelligence and implications for counselling self-efficacy: Phase II. Counsellor Educations \& Supervision, 47, 218-232. doi: 10.1037/0033-295X.84.2.191

Farber, B. A., \& Heifetz, L. J. (1982). The process and dimensions of burnout in psychotherapists. Professional Psychology, 13(2), 293-301. doi: 10.1037/07357028.13.2.293

Glickauf-Hughes, C., \& Mehlman, E. (1995). Narcissistic issues in therapists: Diagnostic and treatment considerations. Psychotherapy, 32, 213-221. doi: 10.1037/0033-3204.32.2.213

Larson, L. M., \& Daniels, J. A. (1998). Review of the counselling self-efficacy literature. The Counselling Psychologist, 26, 179-218. doi: 10.1 177/001 1000098262001

Leary, M. R., Patton, K. M., Orlando, A. E., \& Funk, W. W. (2000). The impostor phenomenon: Self-perceptions, reflected appraisals, and interpersonal strategies. Journal of Personality, 68, 725-756. doi: 10.1111/1467-6494.00114 
Lent, R. W., Cinnamon, R. G., Bryan, N. A., Jezzi, M. M., Helena, M. M., \& Lim, R. (2009). Perceived sources of change in trainees' self-efficacy beliefs.

Psychotherapy Theory, $\quad$ Research, Practice, Training, 46, 317-327. doi: 10. $1037 / \mathrm{aO0} 17029$

Nissen-Lie, H. A., Rønnestad, M. H., Høglend, P. A., Havik, O. E., Solbakken, O. A., Stiles, T. C., \& Monsen, J. T. (2015). Love yourself as a person, doubt yourself as a therapist? Clinical Psychology \& Psychotherapy. doi: 10.1002/cpp.1977

Orlinsky, D. E., Rønnestad, M. H., Ambuhl, H., Willuttzki, U., Botermans, J. F., Cierpka, M., Davis, J., \& Davis, M. (1999). Psychotherapists' assessments of their development at different career levels. Psychotherapy: Theory, Research, Practice, Training, 36, 203-215. doi:10.1037/h0087772

Pompeo, A. M., \& Levitt, D. H. (2014). A path of counselor selfawareness. Counseling and Values, 59(1), 80-94.

Thériault, A., \& Gazzola, N. (2005). Feelings of inadequacy, insecurity, and incompetence among experienced therapists. Counselling and Psychotherapy Research, 5(1), 11-18.

Thériault, A., \& Gazzola, N. (2006). What are the sources of feelings of incompetence in experienced therapists? Counselling Psychology Quarterly, 19(4), 313-330. doi: 10.1080/9515070601090113

Thériault, A., \& Gazzola, N. (2008). Feelings of incompetence among experienced clinicians: A substantive theory. European Journal for Qualitative Research in Psychotherapy, 3, 20-29.

Thériault, A., Gazzola, N., \& Richardson, B. (2009). Feelings of incompetence in novice therapists: Consequences, coping, and correctives. Canadian Journal of Counselling, 43(2), 105-119.

Worthen, V., \& McNeill, B. W. (1996). A phenomenological investigation of "good" supervision events. Journal of Counseling Psychology, 43(1), 25-34. doi: 10.1037/0022-0167.43.1.25 